Vol. XX, No. 1

\title{
Some Saskatchewan Finches
}

Photographed by Doug Gilroy, at Boggy Creek, Regina, 1961

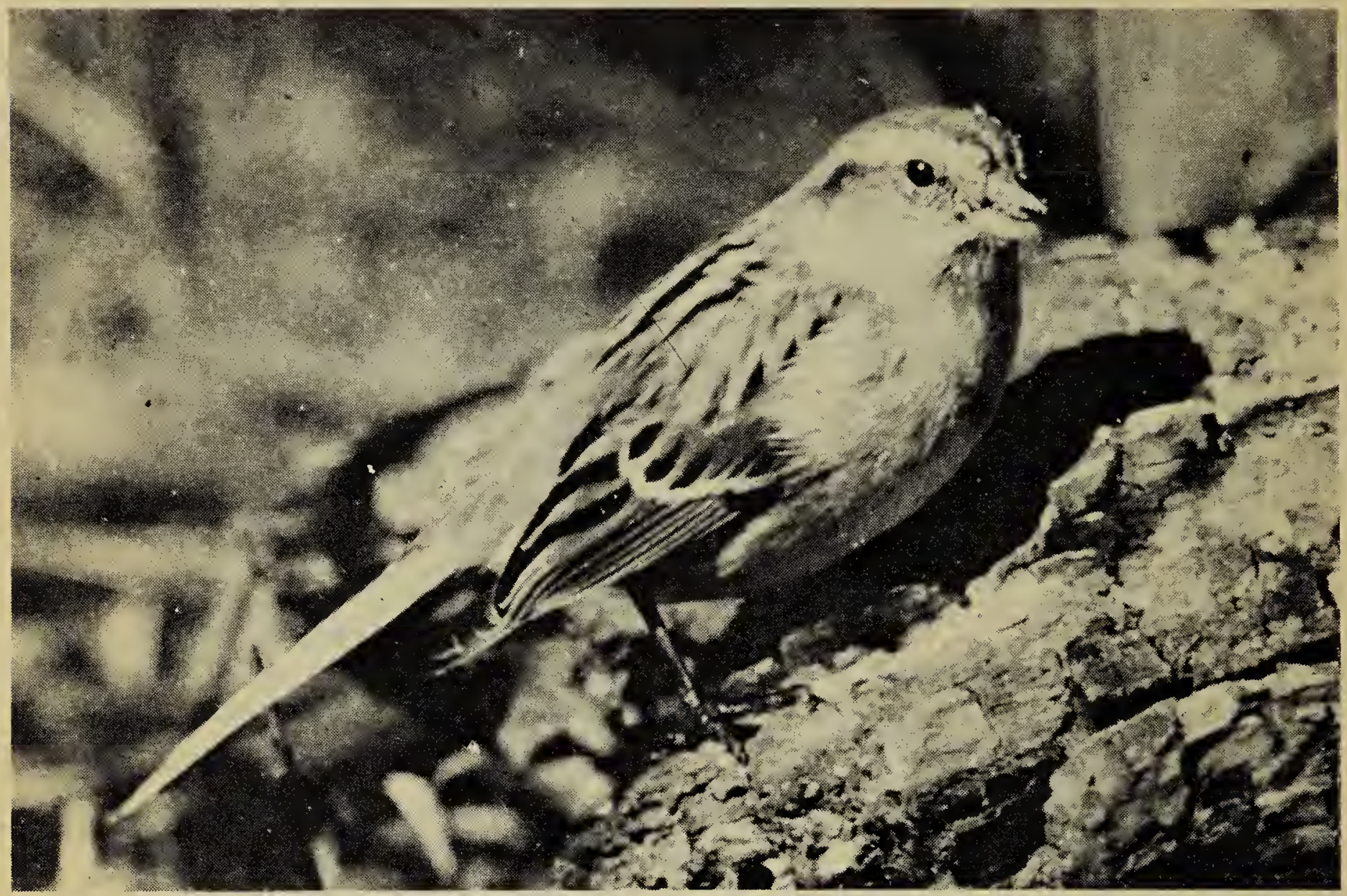

TREE SPARROW, an early spring migrant.

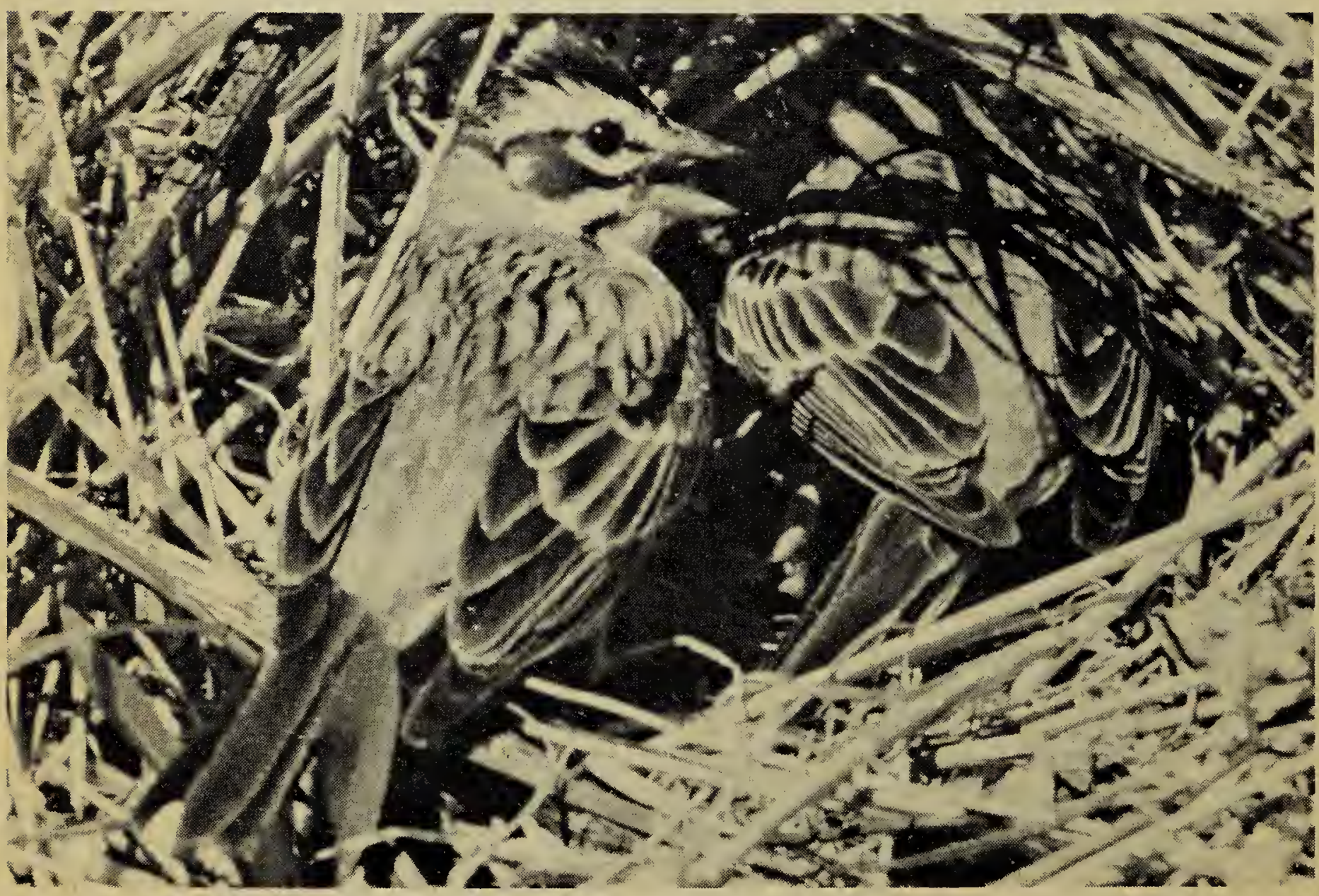

LARK SPARROW at nest. The female remained on the nest to shade the young during the hot weather, and the male brought food to the female and young. 


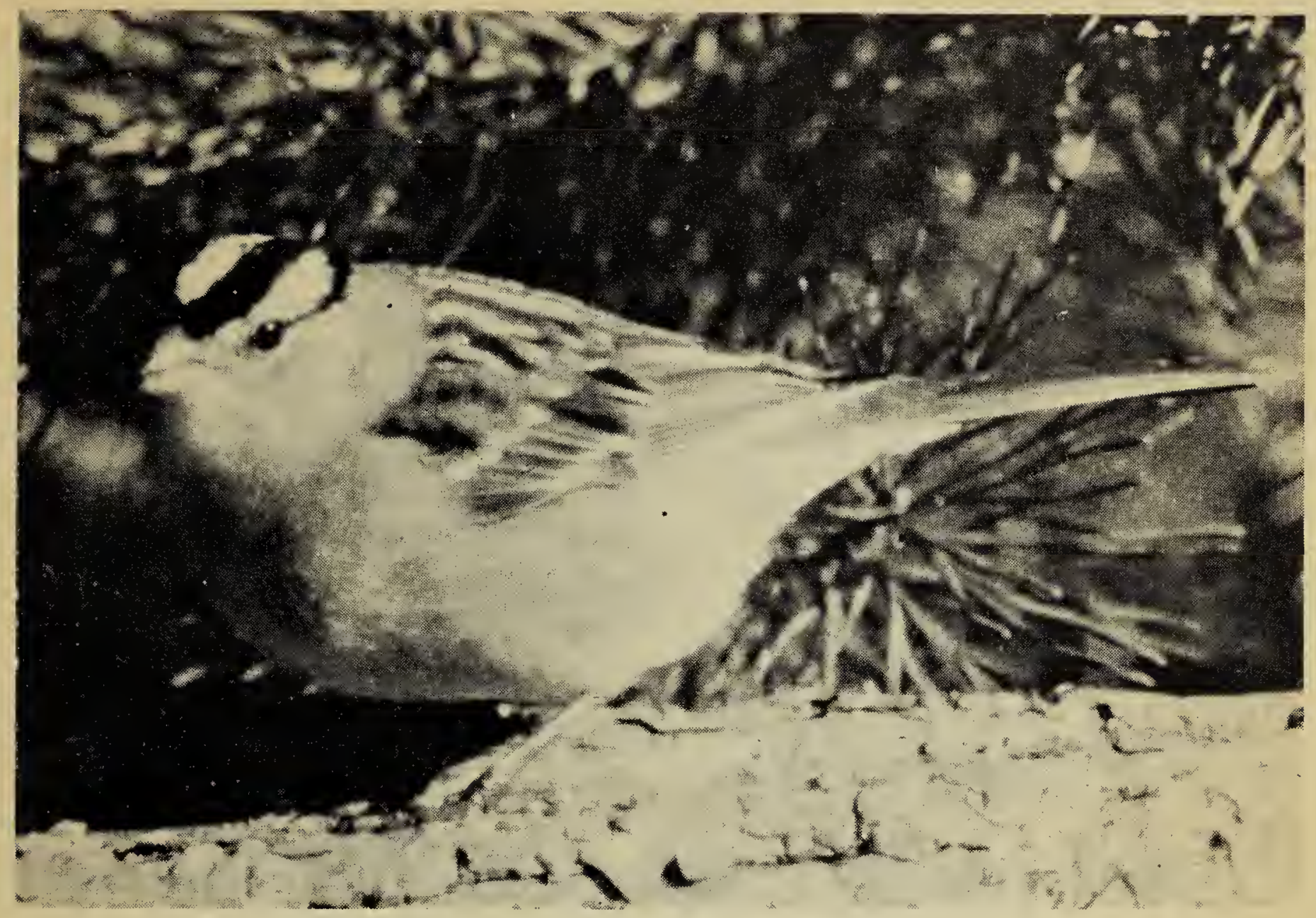

WHITE-CROWNED SPARROW, a conspicuous migrant sparrow.

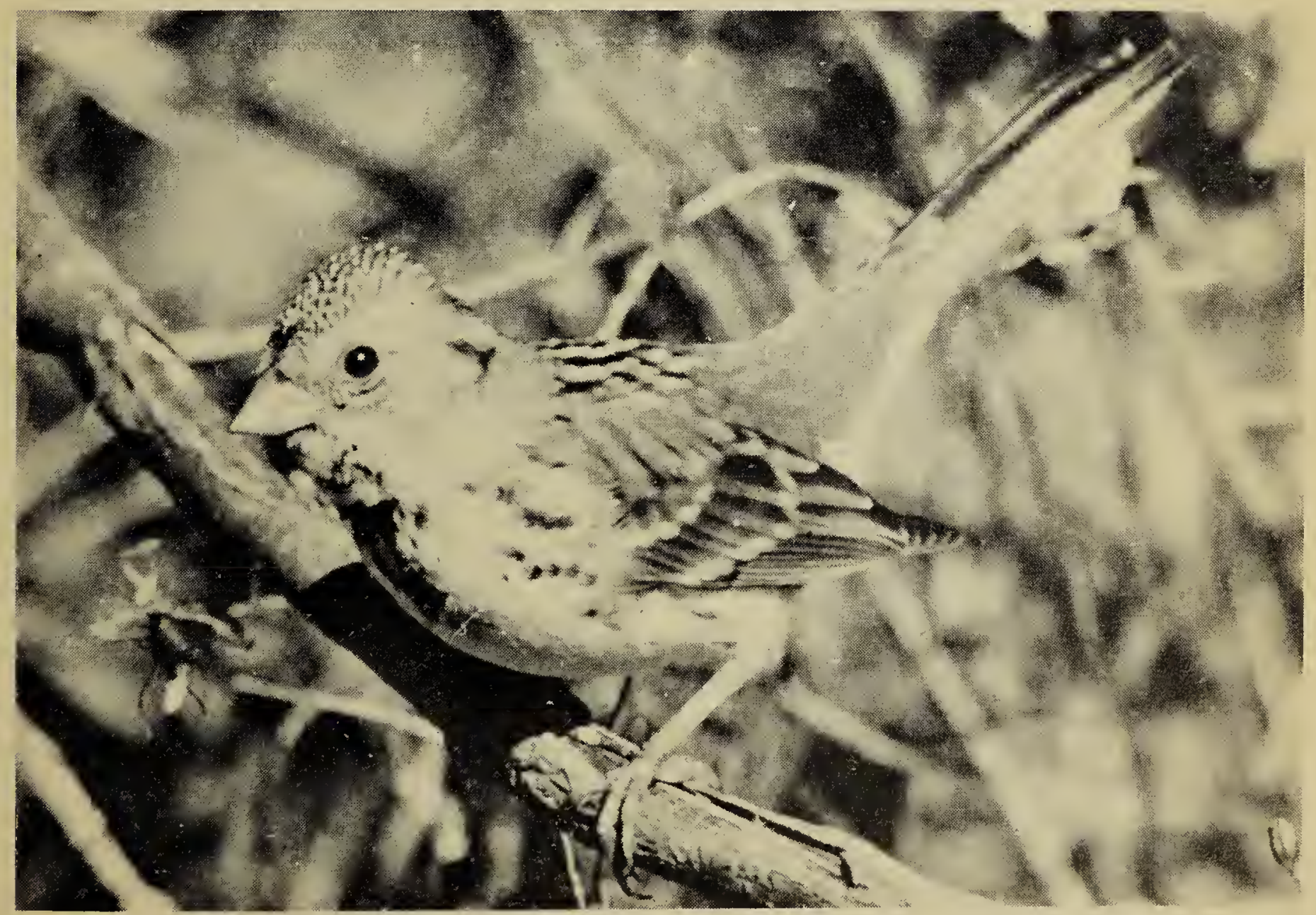

HARRIS' SPARROW in autumn plumage. Note how cardinal-like this pose is. 